\title{
Evaluasi Sistem Proteksi Kebakaran pada Bangunan Hotel UNY 5 Lantai Di Yogyakarta
}

\author{
(Evaluation on Fire Protection System at UNY Hotel Building 5 Floors in Yogyakarta)
}

\author{
MUHAMMAD HERI ZULFIAR, AKHID GUNAWAN
}

\begin{abstract}
Fire is an event that causes many losses. Fire in multi-storey buildings will cause many losses. Some fire events in comersial multi-storey buildings can be used to be mitigation reference to decrease fire risk. Hotel is one of comersial buildings that has a safety standard to the occupants. One of the protection form is making protection for fire hazard. This research is conducted at UNY Hotel located at Karangmalang Street Caturtunggal Depok Sleman Yogyakarta. By this research, hopefully UNY Hotel can be the reference of fire protection system for the others comersial buildings in Yogyakarta.The purpose of this research is to assess the completeness of facilities and infrastructure of fire protection system that available at UNY Hotel. The method is by observation process and assessment of 4 parameters of reliability of building safety system, that are site completeness, rescue device, active protection, and passive protection with reference to Regulation of Minister of Public Works Number 26/PRT/M/2008 about Technical Requirement of Protection System Fire on Building and Environment Building and Fire Safety Building Inspection Guidebook (Pd-T-112005-C) from Research and Development Agency of Ministry of Public Works and several related Indonesian National Standards.The results of the Reliability Building Safety System is 91,60 which means the value of the reliability of the building at UNY Hotel is good. So, UNY Hotel building can be used optimally and building users get protection from fire building hazard.
\end{abstract}

Keywords: Fire, Building Reliability, Fire Protection System

\section{PENDAHULUAN}

Kebakaran merupakan suatu permasalahan yang tidak bisa lepas dari manusia. Kerugian yang diakibatkan oleh kebakaran tidak hanya berupa kerusakan bangunan saja, melainkan juga kerugian yang menyangkut moral dan jiwa manusia. Beberapa penyebab kebakaran antara lain adalah rendahnya pemahaman dan kesadaran masyarakat akan bahaya kebakaran, kurangnya kesiapan masyarakat dalam menghadapi dan menanggulangi bahaya kebakaran, sistem penanganan kebakaran yang belum terwujud dan terintegrasi, serta rendahnya prasarana dan sarana sistem proteksi kebakaran bangunan yang memadai.

Kebakaran dapat mengakibatkan kematian, dan dapat pula menyebabkan keruntuhan struktur yang membahayakan. Kegagalan pengendalian kebakaran dalam bangunan seringkali terjadi disebabkan karena unsur desain bangunan yang kurang baik.

Dalam pasal 4 Peraturan Menteri Pariwisata dan Ekonomi Kreatif Republik Indonesia Nomor PM.53/HM.001/ MPEK/2013 tentang Standar Usaha Hotel disebutkan bahwa setiap usaha hotel wajib memiliki sertifikat dan memenuhi persyaratan standar usaha hotel. Salah satu tujuan standar usaha hotel adalah untuk memberikan perlindungan kepada tamu, pengusaha hotel, tenaga kerja, dan masyarakat, baik untuk keselamatan, kesehatan, kenyamanan, keamanan, dan kemudahan dan pelestarian lingkungan hidup.

Guna melindungi keselamatan pengunjung/ penghuni, bangunan hotel harus memiliki sistem perlindungan sesuai dengan standar yang berlaku, salah satunya adalah sistem proteksi kebakaran. Untuk itu perlu dilakukan evaluasi terhadap sistem proteksi kebakaran dan kondisi 
fisik sistem proteksi kebakaran yang ada pada bangunan hotel.

Definisi sistem proteksi kebakaran pada bangunan gedung dan lingkungan menurut Peraturan Menteri Pekerjaan Umum No. 26/PRT/M/2008 tentang Persyaratan Teknis Sistem Proteksi Kebakaran pada Bangunan Gedung dan Lingkungan adalah sistem yang terdiri atas peralatan, kelengkapan dan sarana, baik yang terpasang maupun pada bangunan yang digunakan baik untuk tujuan sistem proteksi aktif, sistem proteksi pasif, maupun cara-cara pengelolaan dalam rangka melindungi bangunan dan lingkungannya terhadap bahaya kebakaran. Sistem proteksi kebakaran digunakan untuk mendeteksi dan memadamkan kebakaran sedini mungkin dengan menggunakan peralatan yang digerakkan secara manual dan otomatis.

Menurut Pd-T-11-2005-C tentang Pemeriksaan Keselamatan Kebakaran Gedung, komponen utilitas antara lain adalah:

1. Kelengkapan Tapak, komponennya yaitu sumber air, jalan lingkungan, jarak antar bangunan serta hidran halaman.

2. Sarana Penyelamatan, komponennya yaitu jalan keluar, konstruksi jalan keluar dan landasan helikopter.

3. Sistem Proteksi Aktif, komponennya yaitu deteksi dan alarm kebakaran, siames connection, pemadam api ringan, hidran gedung, sprinkler, sistem pemadam luapan, pengendali asap, deteksi asap, pembuangan asap, lift kebakaran, cahaya darurat dan petunjuk arah, listrik darurat, dan ruang pengendali operasi.

4. Sistem Proteksi Pasif, komponennya yaitu ketahanan api struktur bangunan, kompartemensasi ruang, serta pada perlindungan bukaan.

Tujuan penelitian ini adalah untuk melakukan penilaian kelengkapan sarana dan prasarana sistem proteksi kebakaran yang tersedia di Hotel UNY 5 lantai di Yogyakarta. Penilaian dilakukan berdasarkan Buku Pedoman Pemeriksaan Keselamatan Kebakaran Bangunan Gedung (Pd-T-11-2005-C) dari Badan Penelitian dan Pengembangan Kementerian Pekerjaan Umum dan selanjutnya diolah untuk mendapatkan Nilai Keandalan Sistem Keselamatan Bangunan (NKSKB).

\section{METODE PENELITIAN}

\section{Objek Penelitian}

Penelitian ini dilakukan di Hotel UNY yang beralamat di Jl Karangmalang, Caturtunggal, Depok, Sleman, Yogyakarta. Lokasi Hotel UNY dapat dikatakan sangat strategis, karena berada di tengah kota Yogyakarta dan kampus UNY (Universitas Negeri Yogyakarta). Gambar 1 menunjukkan denah bangunan penelitian.

\section{Pengumpulan Data}

Pengumpulan data pada penelitian ini menggunakan 2 cara, yaitu:

\section{Data primer}

Data primer diperoleh dengan cara memeriksa dan mencatat kondisi nyata dari sistem proteksi kebakaran yang ada, baik di dalam maupun di luar gedung hotel, yang meliputi jumlah setiap jenis komponen sistem proteksi kebakaran untuk seluruh bangunan gedung, jumlah setiap jenis komponen sistem proteksi kebakaran pada setiap tingkat, serta jumlah setiap jenis komponen sistem proteksi kebakaran yang rusak/tidak berfungsi.

2. Data sekunder

Data sekunder diperoleh dari beberapa dokumen seperti data gedung dan denah bangunan.

\section{Validasi Data}

Validasi data dilakukan dengan wawancara dengan penyelenggara bangunan gedung.

\section{Pengolahan Data}

Data-data yang diperoleh dari pengamatan langsung dan check list di lapangan selanjutnya digunakan untuk mengetahui penerapan komponen utilitas bangunan terhadap bahaya kebakaran berdasarkan Peraturan Menteri Pekerjaan Umum No:26/PRT/M/2008 dan untuk mengetahui nilai keandalan sistem keselamatan bangunan terhadap bahaya kebakaran berdasarkan Peraturan $\mathrm{Pd}-\mathrm{T}-11-$ 2005-C tentang Pemeriksaan Keselamatan Kebakaran Bangunan Gedung. 


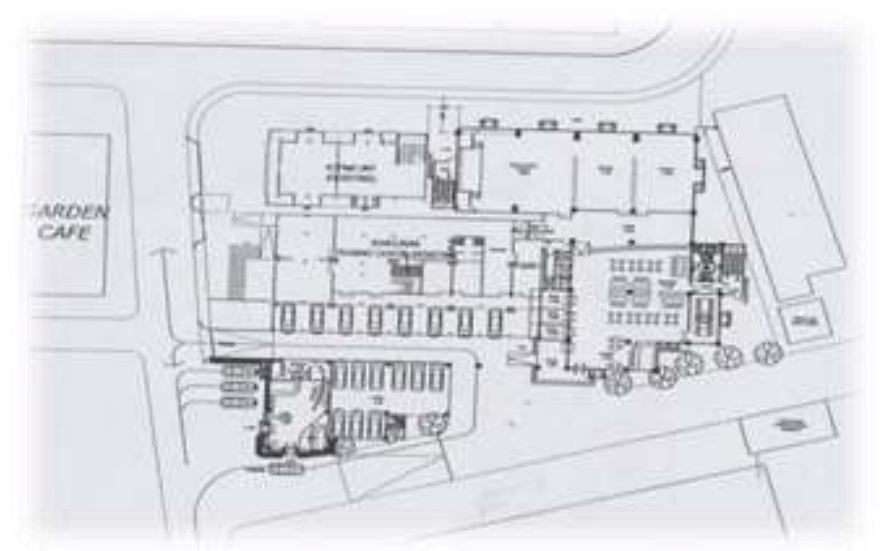

GAMBar 1. Denah Hotel UNY

\section{Kriteria Penilaian}

Kondisi setiap komponen atau bagian bangunan harus dinilai dan dievaluasi. Nilai kondisi komponen proteksi kebakaran bangunan dibagi dalam 3 tingkat, yaitu:

1. Baik : "B" (dengan ekuivalensi nilai B adalah 100).

2. Cukup : "C" (dengan ekuivalensi nilai $\mathrm{C}$ adalah 80).

3. atau Kurang : " $\mathrm{K}$ " (dengan ekuivalensi nilai $\mathrm{K}$ adalah 60 ).

Kriteria-kriteria pada Tabel 1 dipergunakan sebagai bahan acuan praktis penilaian kondisi proteksi kebakaran bangunan yang dilakukan oleh petugas pengelola bangunan.

Penilaian didasarkan pada kriteria atau pembatasan kondisi komponen bangunan yang dikelompokkan menjadi 4 parameter keandalan sistem keselamatan bangunan (KSKB), yaitu:

1. Penilaian komponen kelengkapan tapak.

2. Penilaian komponen sarana penyelamatan.

3. Penilaian komponen proteksi aktif.

4. Penilaian komponen proteksi pasif.

\section{HASIL DAN PEMBAHASAN}

\section{Penilaian Komponen Kelengkapan Tapak}

Penilaian komponen kelengkapan tapak secara menyeluruh seperti yang ditunjukkan pada Tabel 2 memberikan hasil sebesar 23,85 dengan nilai standar maksimal 25. Penilaian yang dianggap cukup yaitu jarak antar bangunan.

Tabel 1. Penilaian Audit Kebakaran

\begin{tabular}{clc}
\hline Nilai & \multicolumn{1}{c}{ Kesesuaian } & Keandalan \\
\hline$>80-100$ & Sesuai persyaratan & Baik (B) \\
\hline $60-80$ & $\begin{array}{l}\text { Terpasang, tetapi ada sebagian kecil } \\
\text { Instalasi yang tidak sesuai persyaratan }\end{array}$ & Cukup (C) \\
\hline$<60$ & Tidak sesuai sama sekali & Kurang (K) \\
\hline & Sumber : Balitbang PU, 2005
\end{tabular}

TABEL 2. Penilaian Komponen Tapak

\begin{tabular}{llccccc}
\hline No & $\begin{array}{c}\text { KSKB/ } \\
\text { SUB KSKB }\end{array}$ & Hasil & $\begin{array}{c}\text { Standar } \\
\text { Penilaian }\end{array}$ & Bobot & $\begin{array}{c}\text { Nilai } \\
\text { Kondisi }\end{array}$ & $\begin{array}{c}\text { Jumlah } \\
\text { Nilai }\end{array}$ \\
\hline KelengkapanTapak & & & 25 & & \\
\hline 1 & Sumber Air & $\mathrm{B}$ & 100 & 27 & 6,75 & \\
\hline 2 & Jalan lingkungan & $\mathrm{B}$ & 100 & 25 & 6,25 & \\
\hline 3 & Jarak antar bangunan & $\mathrm{C}$ & 80 & 23 & 4,60 & \\
\hline 4 & Hidran halaman & $\mathrm{B}$ & 100 & 25 & 6,25 & \\
\hline \multicolumn{7}{l}{} \\
\hline
\end{tabular}


1. Sumber air

Terdapat 2 sumber mata air berasal dari sumur dalam. Untuk memenuhi kebutuhan utama air menggunakan 1 sumur dalam yang terletak di sisi timur hotel, sedangkan satu sumur dalam lain sebagai cadangan. Nilai : baik.

2. Jalan lingkungan

Untuk melakukan proteksi terhadap meluasnya kebakaran dan memudahkan operasi pemadaman, maka di dalam lingkungan bangunan gedung harus tersedia jalan lingkungan dengan perkerasan agar dapat dilalui oleh kendaraan pemadam kebakaran. Pada hotel UNY Jalan lingkungan berada di sisi barat gedung dengan lebar $6,7 \mathrm{~m}$ serta jalan masuk dengan lebar 5,3 m dan semuanya sudah diberi perkerasan. Nilai : baik.

3. Jarak antar bangunan

Dalam upaya melakukan proteksi terhadap meluasnya kebakaran ditentukan jarak minimum antar bangunan gedung. Sisi utara berjarak $11 \mathrm{~m}$ dengan pemukiman/pertokoan. Sisi timur berjarak $1,9 \mathrm{~m}$ dengan gedung Fakultas Ekonomi UNY. Sisi selatan berjarak $13 \mathrm{~m}$ dengan gedung Fakultas MIPA UNY. Sisi barat berbatasan dengan gedung sebelah utara jarak 1,2 $\mathrm{m}$ dengan bangunan kopma UNY, dan gedung sebelah selatan pada sisi barat berhimpit dengan bangunan lama. Nilai : cukup.

4. Hidran halaman

Terdapat 4 unit hidran halaman terpasang dengan kondisi layak, mudah dijangkau serta berfungsi secara sempurna dengan tekanan sesuai dengan persyaratan. Nilai : baik.

Penilaian Komponen Sarana Penyelamatan
Penilaian komponen sarana penyelamatan secara menyeluruh seperti yang ditunjukkan pada Tabel 3 memberikan hasil 25,00 dengan nilai standar maksimal 25.

1. Jalan keluar

Jalan keluar merupakan sarana untuk evakuasi/menyelamatkan diri dari bahaya kebakaran. Pada Hotel UNY sebagian besar kriteria sudah terpenuhi, diantaranya tersedia 2 tangga darurat pada setiap lantainya. Lobby bebas asap sesuai penilaian belum tersedia. Nilai: baik.

2. Konstruksi jalan keluar

Konstruksi jalan keluar dan tangga darurat menggunakan beton tahan api. Pada umumnya kondisi tangga darurat sudah sesuai dengan standar yang ditetapkan, namun di beberapa titik, ruangan kosong di balik pintu darurat digunakan untuk meletakkan beberapa peralatan kebutuhan hotel. Dalam peraturan yang berlaku dinyatakan bahwa tidak diperbolehkan adanya benda-benda yang menghalangi jalan evakuasi jika terjadi kebakaran. Nilai : baik.

3. Landasan helikopter

Landasan helikopter untuk gedung Hotel UNY ini tidak diperlukan dikarenakan persyaratan untuk landasan helikopter hanya untuk gedung dengan ketinggian minimal $60 \mathrm{~m}$. Nilai : tidak ada nilai.

\section{Penilaian Komponen Proteksi Aktif}

Penilaian komponen proteksi aktif secara menyeluruh seperti ditunjukkan pada Tabel 4 memberikan hasil 20,08 dengan nilai standar maksimal 24.

TAbel 3. Penilaian Komponen Sarana Penyelamatan

\begin{tabular}{|c|c|c|c|c|c|c|}
\hline No & $\begin{array}{c}\text { KSKB/ } \\
\text { SUB KSKB }\end{array}$ & Hasil & $\begin{array}{c}\text { Standar } \\
\text { Penilaian }\end{array}$ & Bobot & $\begin{array}{c}\text { Nilai } \\
\text { Kondisi }\end{array}$ & $\begin{array}{c}\text { Jumlah } \\
\text { Nilai }\end{array}$ \\
\hline \multicolumn{4}{|c|}{ Sarana Penyelamatan } & 25 & & \\
\hline 1 & Jalan keluar & B & 100 & 38 & 13,01 & \\
\hline 2 & Konstruksi jalan keluar & B & 100 & 35 & 11,99 & \\
\hline 3 & Landasan helikopter & - & - & 0 & - & \\
\hline \multicolumn{3}{|c|}{ Jumlah } & & & & 25,00 \\
\hline
\end{tabular}


TAbel 4. Penilaian Komponen Proteksi Aktif

\begin{tabular}{|c|c|c|c|c|c|c|}
\hline No & $\begin{array}{c}\text { KSKB/ } \\
\text { SUB KSKB } \\
\end{array}$ & Hasil & $\begin{array}{c}\text { Standar } \\
\text { Penilaian }\end{array}$ & Bobot & $\begin{array}{c}\text { Nilai } \\
\text { Kondisi }\end{array}$ & $\begin{array}{c}\text { Jumlah } \\
\text { Nilai }\end{array}$ \\
\hline \multicolumn{2}{|c|}{ Komponen Proteksi Aktif } & \multicolumn{5}{|c|}{24} \\
\hline 1 & Deteksi dan alarm & $\mathrm{B}$ & 100 & 8 & 2,06 & \\
\hline 2 & Siames Conection & $\mathrm{B}$ & 100 & 8 & 2,06 & \\
\hline 3 & Pemadam Api Ringan & $\mathrm{C}$ & 80 & 8 & 1,65 & \\
\hline 4 & Hidran gedung & B & 100 & 8 & 2,06 & \\
\hline 5 & Sprinkler & $\mathrm{B}$ & 100 & 8 & 2,06 & \\
\hline 6 & Sistem pemadam luapan & $\mathrm{K}$ & 60 & 7 & 1,08 & \\
\hline 7 & Pengendali asap & $\mathrm{K}$ & 60 & 8 & 1,24 & \\
\hline 8 & Deteksi asap & $\mathrm{C}$ & 80 & 8 & 1,65 & \\
\hline 9 & Pembuangan asap & $\mathrm{K}$ & 60 & 7 & 1,08 & \\
\hline 10 & Lift kebakaran & - & - & - & - & \\
\hline 11 & Cahaya darurat dan petunjuk arah & $\mathrm{K}$ & 60 & 8 & 1,24 & \\
\hline 12 & Listrik darurat & $\mathrm{B}$ & 100 & 8 & 2,06 & \\
\hline 13 & Ruang pengendali operasi & $\mathrm{B}$ & 100 & 7 & 1,81 & \\
\hline \multicolumn{6}{|c|}{ Jumlah } & 20,08 \\
\hline
\end{tabular}

Beberapa komponen bernilai kurang yaitu sistem pemadam luapan, pengendali asap, cahaya darurat dan petunjuk arah serta pembuangan asap. Penilaian kurang pada sistem pemadam luapan akan berdampak mempercepat menjalarnya api. Penilaian kurang pada pengendalian asap akan berdampak pada penyebaran asap dalam ruangan lain. Penilaian kurang pada cahaya darurat dan petunjuk arah serta pembuangan asap akan berdampak mengganggu proses evakuasi dan upaya pemadaman.

\section{Deteksi dan alarm}

Deteksi dan alarm pada bangunan ini terdiri atas alarm, alat pemicu manual alarm, detektor panas dan detektor asap dengan perletakan disetiap lantai sudah sesuai dengan persyaratan yang berlaku dan dalam kondisi layak. Nilai : baik.

\section{Siames Conection}

Merupakan sebuah sambungan selang untuk menyuplai air dari mobil pemadam kebakaran. Siames Conection tersedia 1 unit jenis coupling machino, terletak pada sisi barat gedung di tepi Jalan Karangmalang Yogyakarta sangat mudah untuk dijangkau dan dalam kondisi layak. Nilai: baik.

\section{Pemadam api ringan}

Pemadam api ringan menggunakan APAR jenis dry chemical powder kapasitas $3,5 \mathrm{~kg}$ sebanyak 13 buah dan diletakkan tersebar pada setiap lantai. Umumnya alat pemadam api ringan dalam kondisi layak untuk digunakan, namun jarak penempatan antar APAR belum semua sesuai dengan peraturan. Nilai : cukup.

\section{Hidran gedung}

Hidran gedung tersedia sebanyak 9 unit dan terpasang pada lantai 1 sebanyak 2 unit, lantai 2 sebanyak 1 unit, lantai 3 sebanyak 2 unit, lantai 4 sebanyak 2 unit serta di lantai 5 sebanyak 2 unit. Dari kesembilan hidran gedung tersebut semuanya dalam kondisi layak dan lengkap dengan peralatan berupa nozzle maupun selang sepanjang $30 \mathrm{~m}$. Nilai : baik.

\section{Sprinkler}

Jumlah keseluruhan sprinkler terdapat 190 buah, terpasang pada seluruh ruangan bangunan hotel UNY dengan perletakan sesuai persyaratan. Nilai : baik.

6. Sistem pemadam luapan

Sistem tersebut berlaku untuk ruangan/bangunan yang memerlukan sistem khusus seperti ruang komunikasi, ruang komputer, ruang magnetik, ruang elektronik, dan lainnya. Sistem pemadam khusus dapat berupa gas, busa, dan bubuk kering. Gedung ini tidak dilengkapi dengan sistem pemadam luapan. Nilai : kurang.

\section{Pengendali asap}

Pengendali asap merupakan suatu alat yang berfungsi untuk mengendalikan asap yang terdapat di dalam ruangan pada saat terjadi 
kebakaran. Hal ini mengingat bahwa asap tersebut dapat membahayakan jiwa orang yang berada di dalam gedung. Alat ini berupa kipas/fan yang berputar setelah aktifnya detektor asap. Gedung ini tidak dilengkapi dengan pengendali asap. Nilai : kurang.

8. Deteksi asap

Deteksi asap pada bangunan hotel UNY terpasang sebanyak 79 unit dengan pemasangan sesuai syarat yang berlaku, perletakan ada pada setiap kamar dengan kondisi layak. Nilai : cukup.

\section{Pembuangan asap}

Pembuangan asap merupakan suatu alat yang berguna untuk mengeluarkan asap dari dalam ruangan menuju keluar gedung pada saat terjadi kebakaran. Dalam peraturannya setiap reservoir asap dilayani minimal satu buah fun yang mampu menghisap asap. Selain itu fan tersebut terletak di dalam reservoir asap dengan ketinggian $2 \mathrm{~m}$ dari lantai. Alat ini tidak tersedia pada bangunan gedung hotel UNY. Nilai : kurang.

10. Lift kebakaran

Lift kebakaran menurut persyaratan tidak diperlukan karena tinggi efektif gedung tidak mencapai $25 \mathrm{~m}$. Nilai : tidak ada nilai.

11. Cahaya darurat dan petunjuk arah

Tidak ditemukan cahaya darurat terpasang pada tangga darurat, hanya terpasang pada jalan terusan serta pada tanda exit dan dapat menyala secara otomatis. Petunjuk arah jalur evakuasi juga terpasang dengan jelas pada tangga darurat. Nilai : kurang.

\section{Listrik darurat}

Listrik darurat menggunakan generator berkapasitas $500 \mathrm{KVA}$ dan dapat beroperasi secara otomatis jika listrik padam dengan time delay 10 menit. Nilai : baik.
Peralatan yang terdapat dalam ruang pengendali operasi diantaranya monitor pemantau, sound system, alat komunikasi, panel kontrol alarm, dan panel kontrol kelistrikan yang dapat memantau langsung bahaya kebakaran yang terjadi dan mampu bereaksi dengan cepat langsung dari pengendali operasi secara otomatis dengan pengawasan 24 jam dari teknisi dan satuan pengamanan. Nilai : baik.

\section{Penilaian Komponen Proteksi Pasif}

Penilaian komponen proteksi pasif secara menyeluruh seperti ditunjukkan pada Tabel 5 memberikan hasil 22,67 dengan nilai standar maksimal 26. Komponen yang bernilai kurang adalah perlindungan bukaan. Penilaian kurang ini akan berdampak pada sulitnya petugas pemadam kebakaran untuk masuk ke dalam gedung.

1. Ketahanan api struktur bangunan

Ketahanan api komponen struktur bangunan sudah sesuai dengan persyaratan Tipe A, yaitu konstruksi yang struktur pembentuknya tahan api dan mampu menahan secara struktural tarhadap beban bangunan. Nilai : baik.

2. Kompartemenisasi ruangan

Kompartemenisasi ruangan berupa tembok yang memisahkan antar kamar hotel serta telah dilengkapi dengan sprinkler pada tiap ruangan namun untuk sistem pembuangan asap tidak terpasang dalam bangunan ini. Jalan lingkungan dengan lebar 6,7 m cukup untuk akses mobil pemadam masuk ke lokasi. Nilai: baik.

\section{Perlindungan bukaan}

Dalam bangunan gedung ini tidak ditemukan bukaan untuk akses petugas pemadam kebakaran, pintu bukaan pada shaft pipa maupun shaft instalasi kabel terbuat dari kayu lapis yang tidak tahan api. Nilai : kurang.

13. Ruang Pengendali Operasi

Tabel 5. Penilaian Komponen Proteksi Pasif

\begin{tabular}{|c|c|c|c|c|c|c|}
\hline No & $\begin{array}{c}\text { KSKB/ } \\
\text { SUB KSKB } \\
\end{array}$ & Hasil & $\begin{array}{c}\text { Standar } \\
\text { Penilaian }\end{array}$ & Bobot & $\begin{array}{c}\text { Nilai } \\
\text { Kondisi }\end{array}$ & $\begin{array}{c}\text { Jumlah } \\
\text { Nilai }\end{array}$ \\
\hline \multicolumn{2}{|c|}{ Komponen Proteksi Pasif } & & & 26 & & \\
\hline 1 & Ketahanan struktur bangunan & $\mathrm{B}$ & 100 & 36 & 9,36 & \\
\hline 2 & Kompartemenisasi ruang & $\mathrm{B}$ & 100 & 32 & 8,32 & \\
\hline 3 & Perlindungan bukaan & $\mathrm{K}$ & 60 & 32 & 4,99 & \\
\hline \multicolumn{2}{|c|}{ Jumlah } & & & & & 22,67 \\
\hline
\end{tabular}


TABEL 6. Komponen Sistem Keselamatan Bangunan

\begin{tabular}{clcc}
\hline No & \multicolumn{1}{c}{ Parameter } & Bobot KSKB $(\%)$ & Nilai \\
\hline 1 & Kelengkapan tapak & 25 & 23,85 \\
\hline 2 & Sarana penyelamatan & 25 & 25,00 \\
\hline 3 & Sistem proteksi aktif & 24 & 20,08 \\
\hline 4 & Sistem proteksi pasif & 26 & 22,67 \\
\hline \multicolumn{2}{c}{ Jumlah nilai } & 91.60 \\
\hline
\end{tabular}

\section{Hasil Penilaian Komponen Sistem Keselamatan Bangunan}

Hasil penilaian dan perhitungan komponen sistem keselamatan pada bangunan Hotel UNY dapat dilihat pada Tabel 6. Dari Tabel 6 tersebut diperoleh Nilai Keandalan Sistem Keselamatan sebesar 91,60; yang menunjukkan bahwa kondisi gedung secara menyeluruh termasuk di dalam kategori "Baik". Dengan demikian, bangunan Hotel UNY dapat digunakan secara optimal dan pengguna bangunan mendapat perlindungan yang baik dari bahaya kebakaran bangunan.

\section{KESIMPULAN}

1. Hasil perhitungan nilai komponen utilitas di hotel UNY menghasilkan Nilai Keandalan Sistem Keselamatan Bangunan (NKSKB) sebesar 91,60. Hal ini menunjukkan nilai keandalan bangunan dalam kategori baik dan sesuai dengan peraturan yang berlaku.

2. Berdasarkan hasil penilaian bahwa Hotel UNY belum dapat dijadikan rujukan penerapan sistem proteksi kebakaran pada bangunan komersiil di Yogyakarta karena ada beberapa komponen yang tidak terpasang.

\section{DAFTAR PUSTAKA}

BSN. (2000). SNI 03-1735-2000 : Tata Cara Perencanaan Akses Bangunan Dan Akses Lingkungan Untuk Pencegahan Bahaya Kebakaran Pada Bangunan Gedung.

BSN. (2000). SNI 03-1736-2000 : Tata Cara Perencanaan Sistem Proteksi Pasif untuk
Pencegahan Bahaya Kebakaran pada Bangunan Rumah dan Gedung.

Kemenpu. (2008). Peraturan Menteri Pekerjaan Umum Nomor 26 Tahun 2008 Tentang Persyaratan Teknis Sistem Proteksi Kebakaran pada Bangunan Gedung dan Lingkungan.

Kementerian Pariwisata dan Ekonomi Kreatif (2013). Peraturan Menteri Pariwisata dan Ekonomi Kreatif Republik Indonesia Nomor PM.53/HM.001/MPEK/2013 tanggal 27 September 2013 Tentang Standar Usaha Hotel.

Saptaria, Erry, dkk. (2005). Pd-T-11-2005-C Pedoman Teknis Pemeriksaan Keselamatan Kebakaran Bangunan Gedung. Bandung: Puslitbang Pemukiman Badan Penelitian dan Pengembangan PU, Departemen Pekerjaan Umum

PENULIS:

\section{Muhammad Heri Zulfiar}

Program Studi Teknik Sipil, Fakultas Teknik, Universitas Muhammadiyah Yogyakarta, Yogyakarta.

Email: zulfiarheri@gmail.com

\begin{abstract}
Akhid Gunawan
Program Studi Teknik Sipil, Fakultas Teknik, Universitas Muhammadiyah Yogyakarta, Yogyakarta.
\end{abstract}

Email: akhid.gunawan.1997@ft.umy.ac.id 